\title{
Development of Manufacturing Technology for Electric Resistance Welded Steel Pipes with Ultra-heavy Wall Thickness
}

\author{
Tsuneharu YAZAWA, Katsuyuki SUGA, Tetsuro SUGAYOSHI, ${ }^{1)}$ Joji OHWAKI, Yoshifumi \\ FUJIOKA $^{2)}$ and Yuji SUGIMOTO
}

Keihin Works, NKK Corporation, Minamiwatarida-cho, Kawasaki-ku, Kawasaki, Kanagawa-ken, 210 Japan. $\quad$ 1) Head Office, NKK Corporation, Marunouchi, Chiyoda-ku, Tokyo, 100 Japan. ken, 235 Japan.

2) Kokan Kenzai Corporation, Shin-isogo-cho, Isogo-ku, Yokohama, Kanagawa-

(Received on September 14, 1990; accepted in final form on December 14, 1990)

\begin{abstract}
NKK has developed new manufacturing techniques to meet the increasing need for electric resistance welded (ERW) steel pipe with heavier wall thickness and higher quality. These new advances overcome problems encountered with conventional ERW methods by incorporating new technology in forming, welding, quality assurance, and other processes. This has enabled the production of high quality electric resistance welded steel pipe with ultra-heavy wall thicknesses in a wide range of sizes. The new advances that comprise this manufacturing technology are presented in this report.
\end{abstract}

KEY WORDS : electric resistance welded steel pipe ; roll forming ; ultra heavy wall thickness pipe ; welding ; non destructive inspection ; dimensional accuracy; t/D.

\section{Introduction}

Electric resistance welded (ERW) steel pipe has been produced primarily in thin wall thicknesses because of limitations in the manufacturing process. The use of ERW pipes has expanded with improvements in the quality of the raw materials and the remarkable progress that has been made in forming, welding, and non-destructive inspection technology. Thus the need has increased for the development of ultra-heavy wall ERW pipes in seamless pipe sizes that maintain the good appearance and high dimensional accuracy of cold roll forming.

To meet the need for ultra-heavy wall pipes, NKK developed a manufacturing technology the focuses on a new composite forming technology. The development of this manufacturing technology has enabled the production of ERW pipe with a ratio of wall thickness to outside diameter (t/D) of $26 \%$, significantly exceeding the ratio $20 \%$ that was said to be the upper limit.

\section{Outline of New Technology}

Problems encountered in manufacturing ultra-high wall ERW pipes are extensive and are not limited to forming and welding. High-quality pipes can be produced only after these problems have been overcome.

Some of the new technology that has been applied to ERW pipe manufacturing at the NKK Keihin Works in shown in Fig.1. The production of ultra-heavy wall pipes with high dimensional accuracy and high quality is not possible using conventional technology.

This report presents the following major advances that comprise the new manufacturing process for ultra-heavy wall ERW pipe:
1) NKK-type composite forming technology (NCF),

2) Welding heat input control and monitoring system (ERTBC), and

3) Ultrasonic testing technology for ultra-heavy wall ERW pipe.

\section{NKK-type Composite Forming Technology}

\subsection{Problems and Limitations of Conventional Technol-} ogy

Figure 2 presents the available size range of conventional ERW pipe.

In the production of ERW pipe, an increase in the ratio of wall thickness to outside diameter $(t / D)$ results in a deformation at the edge that is caused by the slitter, a decrease in the edge wall thickness that occurs at the initial stage of breakdown and a lack of edge forming, that results in poor dimensional accuracy. These produce variations in the wall thickness and inside roundness of the finished pipe, as shown in Figs 3 to 5 .

In addition, the lack of edge formation and the large difference in circumference length between the inside and outside surfaces cause peaking of the electric resistance butt weld. The peaked shape reduces the weld quality and makes cutting the inside bead impossible. This is a serious problem for producing ERW pipe and has limited the $\mathrm{t} / \mathrm{D}$ ratio to $20 \%$. The shape of a butt joint in thick-wall pipe formed by the conventional ERW process is shown in Fig.6.

\subsection{Features of NKK-type Composite Forming Technol- ogy}

The new forming technique developed by NKK has enabled the forming and welding of ultra-heavy wall ERW pipe. This new technology has the following features: 


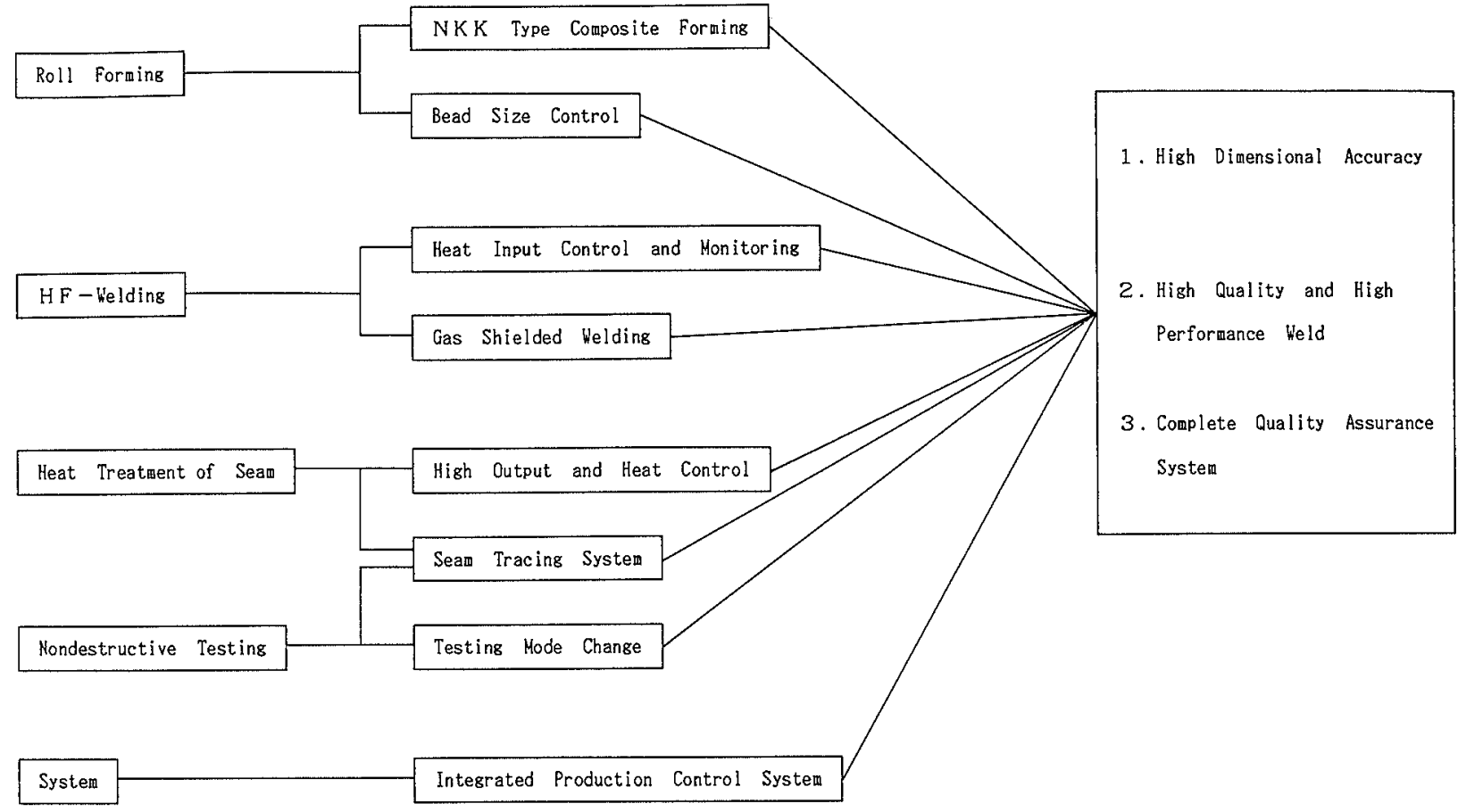

Fig.1. New technology in each process.

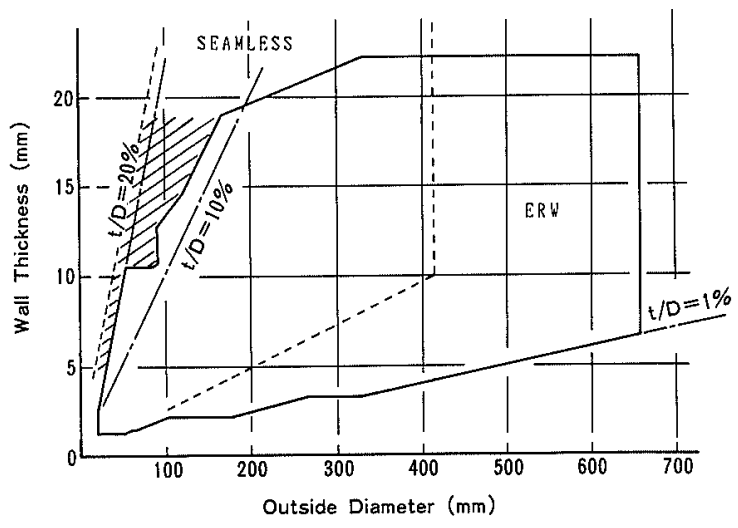

Fig.2. Available size range of conventional ERW pipe.

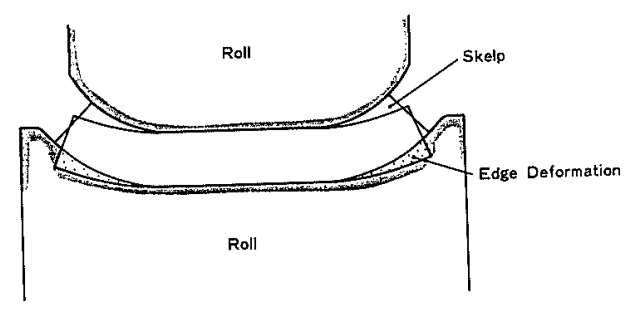

Fig.3. Deformation at the skelp edge affected by slitting.

(1) The thickness at the edge is increased by the use of an edge upsetter;

(2) Thinned or deformed edges are cut by the use of an edge milling machine;

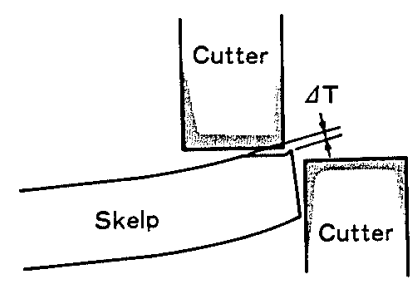

Fig.4. Deformation at the skelp edge affected by B.D. forming.

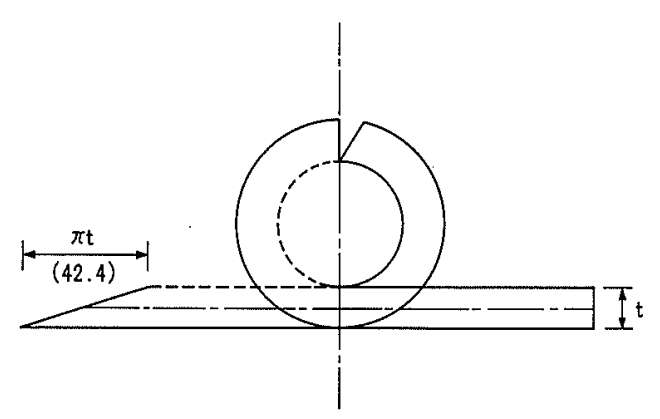

$(13.5)$

Fig.5 . Difference of circumferential length between I.D. and O.D.

(3) The edge is replenished and restrained during breakdown roll forming;

(4) The same roll is used to form pipe from thin to ultraheavy wall thickness.

Figures 7 to 9 schematically show the features of NKKtype composite forming technology.

The sequence of forming is as follows: First, pretreatment 
is performed by increasing the edge thickness using an upset roll. Edges that are thinned or deformed by the slitter are cut with an edge milling machine at the same time. The cutter is set an angle to the upset roll to reduce the difference in circumstance length between the inside and outside of the pipe.

Next, rolling is performed using the thickened edge to fill the space between the breakdown rolls. This technique enables edge forming without a decrease in wall thickness.

Normally, the difference in circumference length between the inside and outside surfaces of the pipe increases as forming proceeds. With this new technology, the difference in circumference is corrected at each stage by replenish rolling in each stand of up and down and side breakdown rolls, providing pipes with uniform wall thickness.

This technique also allows the use of the same roll to form pipe from thin to ultra-heavy wall thickness $(2.1-13.5 \mathrm{~mm})$. This is a unique feature that is not found in other mills.

\subsection{Application Results of NKK Composite Forming Technology}

The result of the use of this new technology for forming a pipe with an outside diameter of $42.7 \mathrm{~mm}$ and a wall thickness of $11.0 \mathrm{~mm}(\mathrm{t} / \mathrm{D}=26 \%)$ is described below. Test pipe is carbon steel for mechanical structural purposes (Tensile Strength $=490 \mathrm{~N} / \mathrm{mm}^{2}$ ).
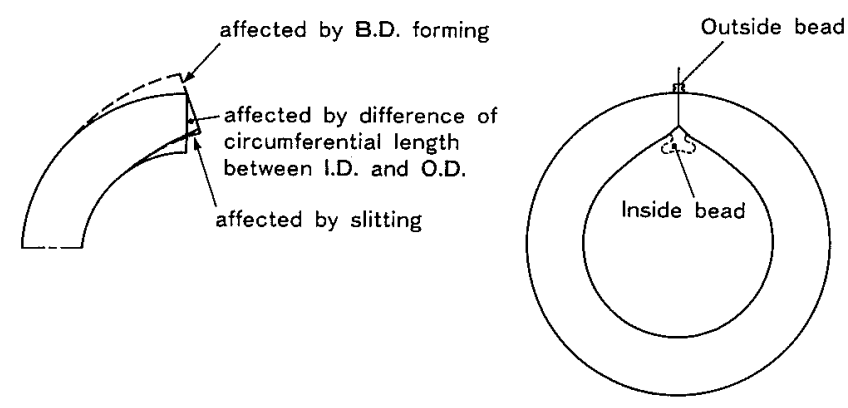

Fig.6. Cross section of the typical heavy wall thickness ERW produced by conventional method.

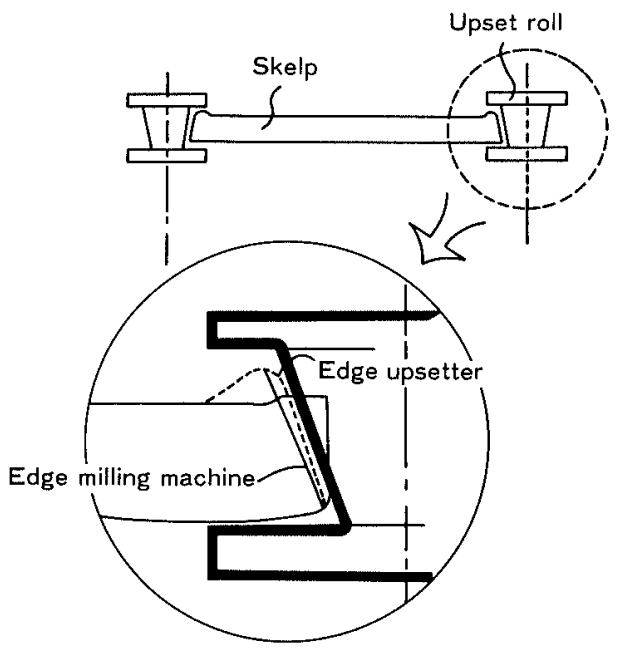

Fig.7. Method of edge forming.
The profiles at each forming process are shown in Fig.10 and the change in the distribution of wall thickness is shown in Fig.11. These results reveal that the decrease in edge wall thickness and the lack of edge forming found in the conventional process have been eliminated. An I-shaped butt joint is assured by the edge pretreatment and new edge forming techniques. As can be seen from the change in the distribution of wall thickness near the edge, the increased edge wall thickness from the edge pretreatment assures the formation of pipe with a uniform wall thickness and without a decrease in wall thickness at the edge.

Figure 12 shows a comparison of cross sections of finished thick-wall pipe formed by the new and conventional methods. Non-uniform wall thickness, inside out-of-round-

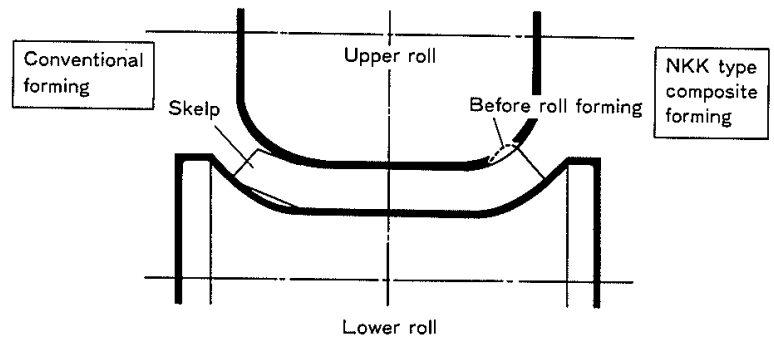

Fig.8. Edge replenished rolling in the first breakdown roll.

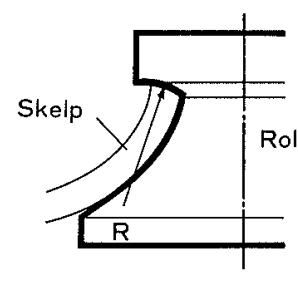

(Side roll)

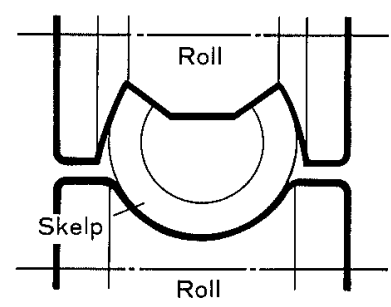

(Upper and lower roll)
Fig.9. Edge restrained rolling in the breakdown zone.

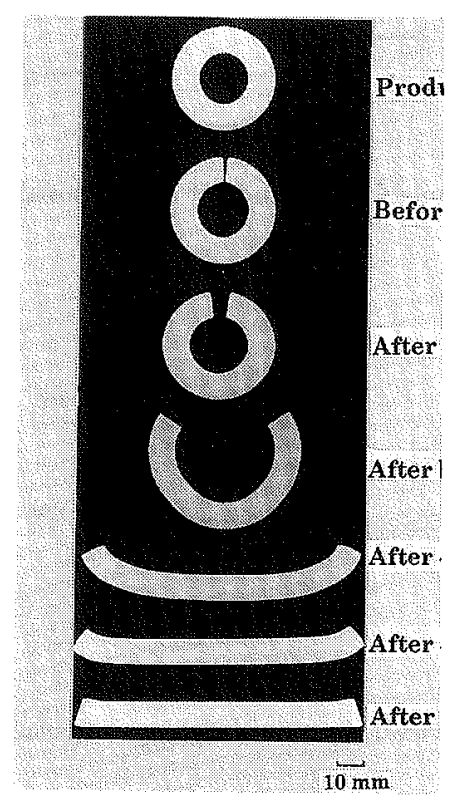

Fig.10. NKK-type composite forming profile $(42.7 \mathrm{~mm} \phi$ $11.0 \mathrm{mmt}$ ). 
ness, and weld peaking can be seen in the conventional process pipe, but are not found in the pipe made with the new process. Uniform size and shape are assured, despite the ultra-heavy wall thickness and a t/D ratio of $26 \%$.

\section{Welding Heat Input Control and Monitoring System (ER-TBC)}

Rigorous heat input control must be exercised in electric resistance welding to ensure good accuracy and quality. Heat input needs to be low enough to allow the weld bead to be trimmed on-line with a small cutter after welding. This is

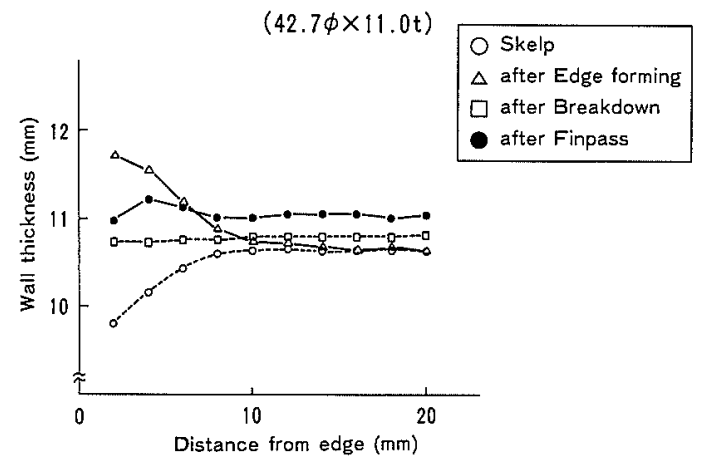

Fig.11. Change in wall thickness distribution of NKK-type composite forming profile $(42.7 \mathrm{~mm} \phi \times 11.0 \mathrm{mmt})$.

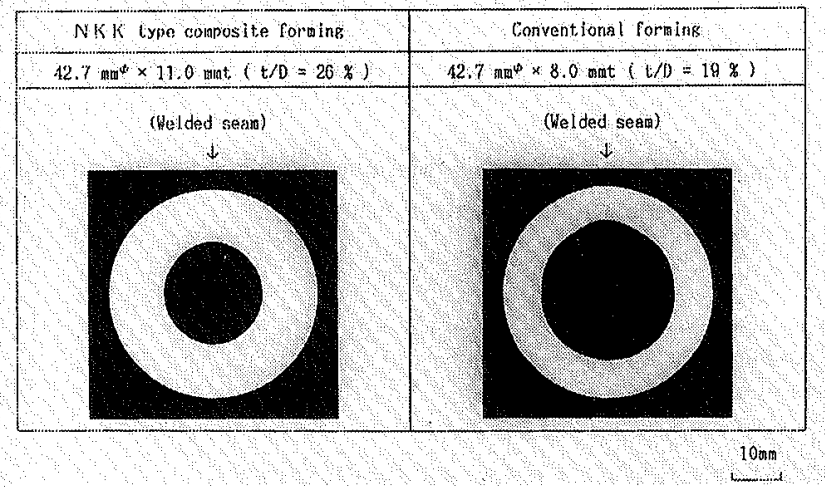

Fig.12. Typical examples of product cross section. necessary because only a small cutter can be inserted into the thicker-wall pipe which has a inside diameter that is smaller. However, if the heat input is reduced too much, the weld quality will deteriorate. Thus, heat input control is critical.

As shown in Fig.13 peak temperature, which is typically used as a parameter for conventional control systems, is lacking in linearity and cannot be controlled, particularly in the overheat region. Control of the size of the heated area has also been used, but it has poor responsiveness. Neither of these parameters is practical. For these reasons, NKK developed a new welding heat input control and monitoring system (ER-TBC), that has the following features:

(1) The heated width is used as a control parameter for heat input control;

(2) Continuous monitoring of the bead shape is performed by the light sectioning method.

Figure 14 shows the configuration of this system.

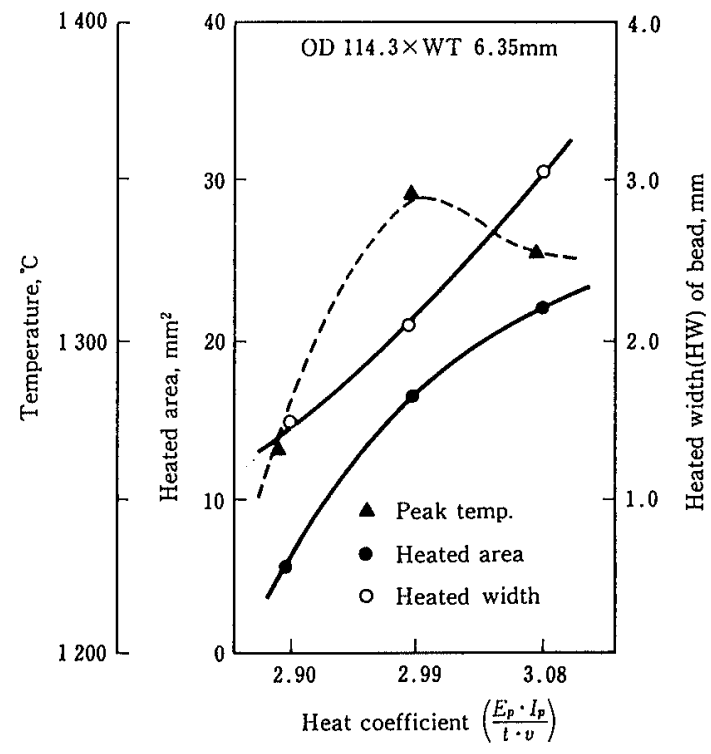

Fig.13. Relation between parameters and heat coefficient.

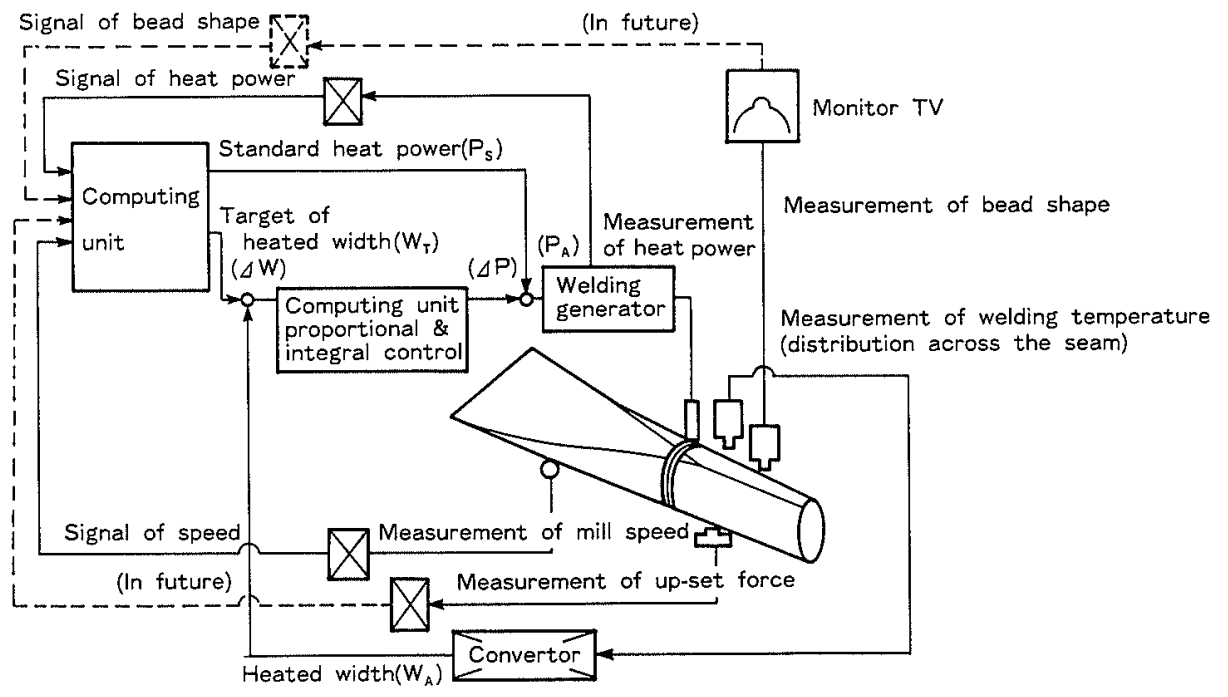

Fig.14. Configuration of automatic heat input control system (ER-TBC). 
The feedback and feedforward control systems are used to control welding. The feedback system controls the width of the heated zone using a linear array temperature distribution meter for a sensor. The feedforward control system computes and outputs the quantity of heat input in accordance with operating conditions such as the type of material, pipe wall thickness and welding speed (see Fig.15).

A bead shape meter using the light sectioning method was adapted to continuously monitor the welding condition. Figures 16 and 17 indicate that the bead shape obtained by the light sectioning method agreed well with the actual cross section of the weld bead (see Fig.18).

The integrated heat input control and bead shape monitoring system (ER-TBC) for ERW pipes is effective throughout the welding range from poor weld to overheat. This system has been used in all of NKK's ERW pipe manufacturing

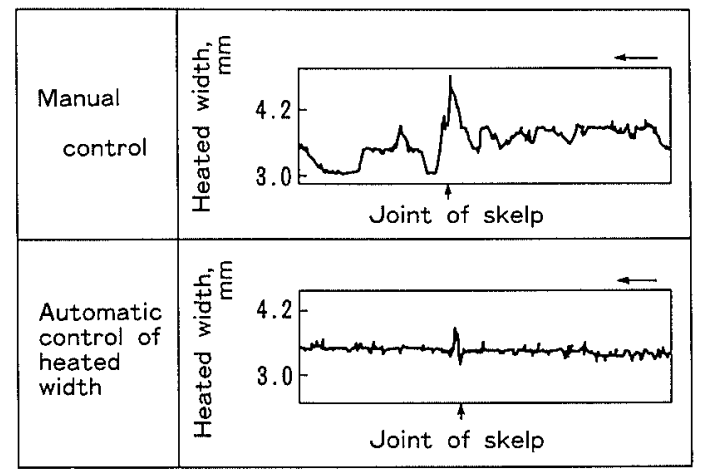

Fig.15. Typical examples of heat input results in the case of manual and automatic control. lines under a wide range of operating conditions, such as the type of material, pipe size, and welding speed, and contributes to the uniform improvement of welding quality.

\section{Ultrasonic Testing Technology for Ultra-heavy Wall ERW Pipe}

To ensure quality, an ultrasonic flaw detector is located

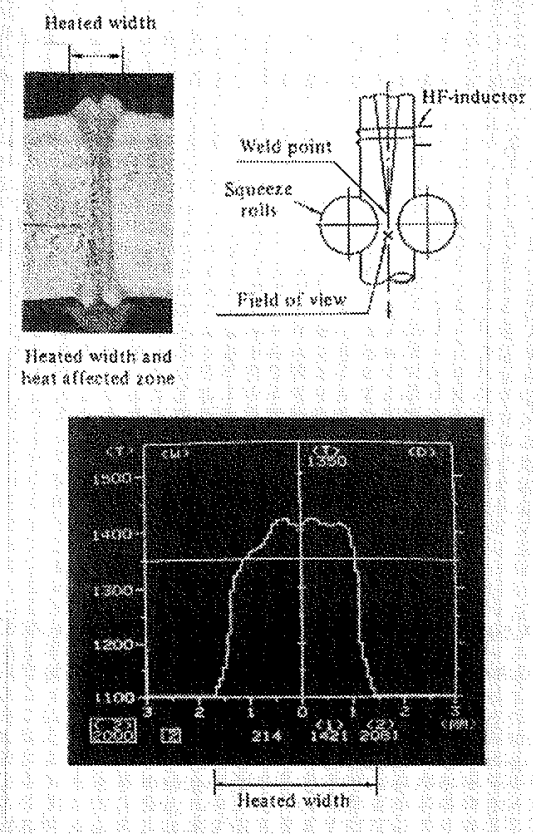

Fig.16. Temperature distribution on the welded tube surface measured by a linear array.

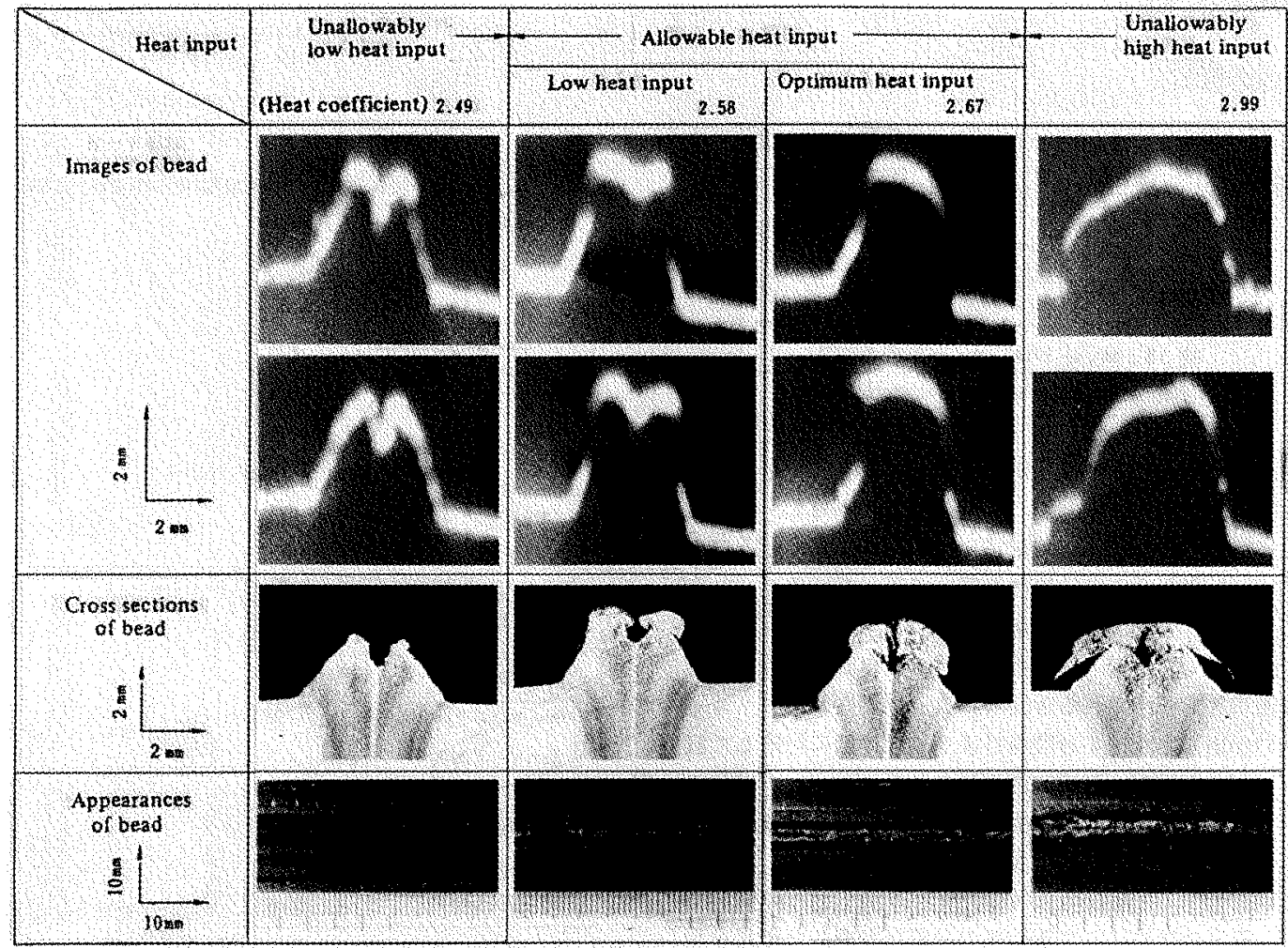

Fig.17. Changes of bead shape with heat input 
just after the welding process. This machine has the following features:

1) The detection by the change of mode between longitudinal and shear wave propagation;

2) The use of a seam tracing unit that enables detection just after welding.

Ordinary ultrasonic angle beam testing with shear wave have so far been unable to detect flaws on pipes with $t / D$ ratio exceeding $20 \%$ because the ultrasonic beam does not reach the inner surface. Therefore, a method to detect internal defects using the change of mode between longitudinal and shear waves at the outer surface of the pipe has been developed (see Fig.19).

On ultra-heavy wall pipes, the weld is prone to twist so that an ultrasonic beam cannot be aimed exactly at the internal weld. Conventional ultrasonic testing of thick-wall pipes is usually carried out by rotating the pipe or probe during the final stage of production, making the early feedback of quality information impossible. NKK's new technology, incorporating both the NKK-developed seam tracing unit with

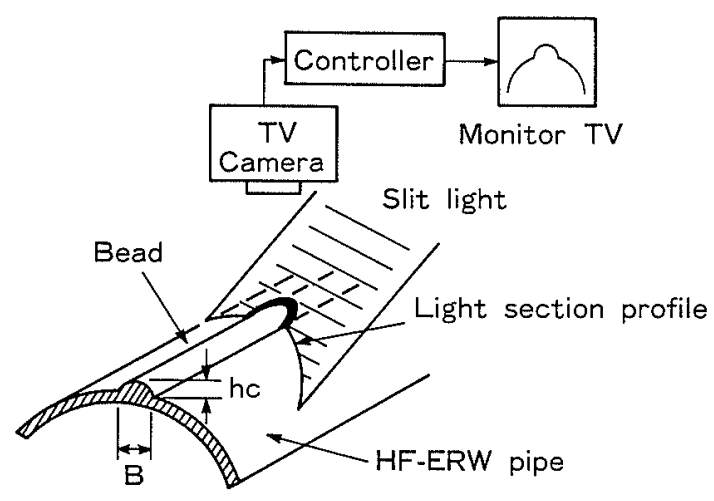

Fig.18. Principle of measurement of bead shape.

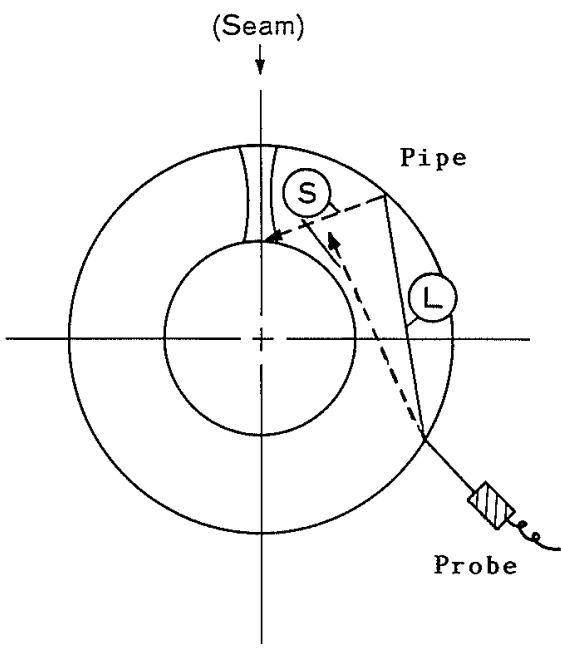

Fig.19. Changes of testing mode S : Shear Wave, L : Longitudinal Wave. its optical seam detector and the mode change technique, has enabled ultrasonic testing to be carried out immediately after welding (see Fig.20).

\section{Quality and Applications of Product}

Figure 21 shows the size range of pipe that can now be produced by the small-diameter ERW pipe mill. This range includes ultra-heavy wall pipe with t/D ratios up to $26 \%$ by using the new technology.

These pipes have a very consistent weld quality and dimensional accuracy throughout the range from thin to ultra-heavy wall thickness. This uniformity is ensured by the quality assurance system that fully utilizes the stable formability, precise welding heat input control, high output seam annealer, enhanced ultrasonic flaw detection and other benefits of the new technology. Dimensional accuracy is especially improved over that obtained by conventional methods, not only in the region where $\mathrm{t} / \mathrm{D}$ exceeds $20 \%$, but also in the conventional size region (Figs. 22 and 23).

The main applications are tubulars for machine structural

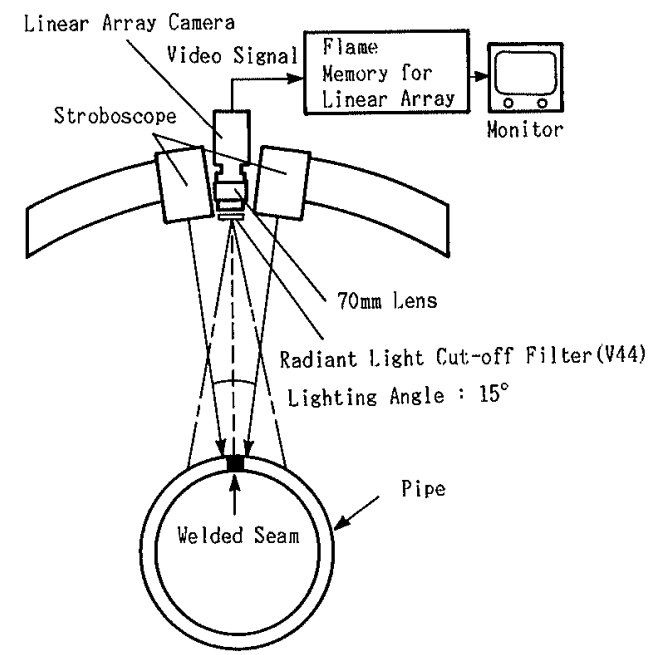

Fig.20. Seam detector.

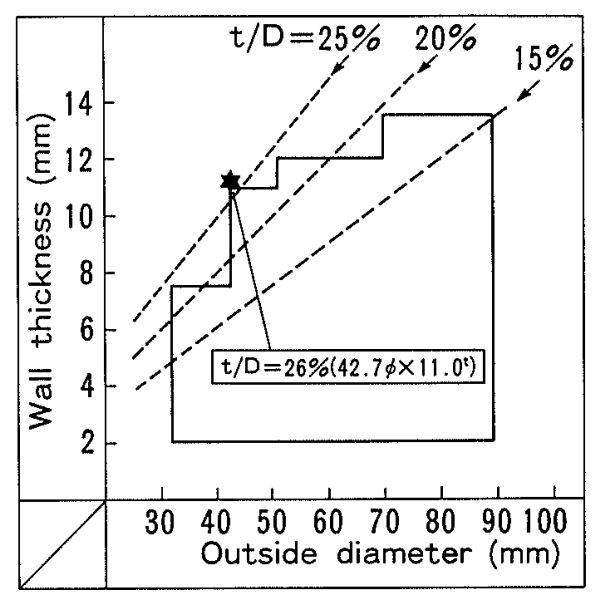

Fig.21. Available size range of small diameter ERW pipe mill. 


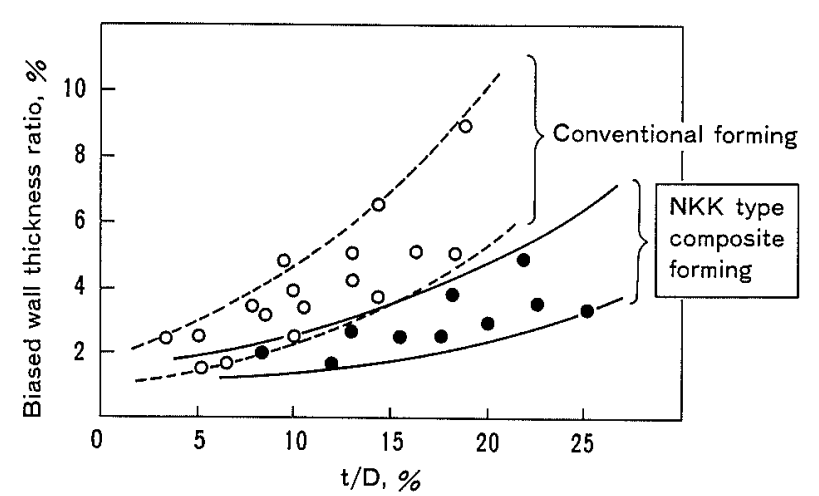

Fig.22. Comparison of biased wall thickness ratio.

purposes, including automotive and construction machinery, as well as for the energy, construction and chemical plant engineering sectors.

\section{Concluding Remarks}

Electric resistance welding is the most common method for manufacturing steel pipes. However, the range of pipes manufactured by this method needs to be extended to higher quality and greater thicknesses because of its high produc-

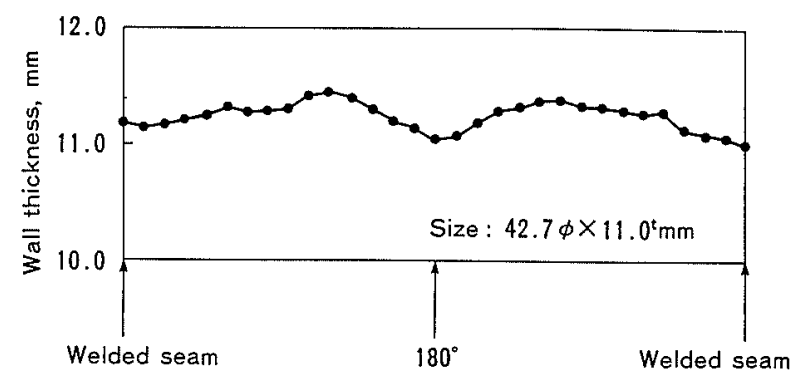

Fig.23. Wall thickness distribution.

tivity, excellent dimensional accuracy and good appearance. Conventional ERW technology has not fully met these requirements.

The forming, welding, and quality assurance advances described in this report constitute a major breakthrough for producing ultra-heavy wall ERW pipe. The new production systems have also achieved a high level of quality that has not been available using conventional technology. These advances have also had a significant effect on fields other than manufacture of ERW pipe. 